\title{
Estimation of genetic and environment trend for birth weight and weaning weight in Najdi calves
}

Bahareh Taheri Dezfuli, Sima Savar Sofla, MohammadReza Mashayekhi

Agricultre and Natural Resources Research Center of Khuzestan, Ahwaz, Islamic Republic of Iran

Email: bahareh_tah2003@yahoo.com

Introduction The Najdi cow is native to Khuzestan province. Native cattle have some advantages over exotic breeds such as resistance to disease and use of native pastures with reduced food cost. In order to evaluate genetic improvement in a selected population, variation resulted from environment and genetic should be disentangled. This work required the estimation of genetic parameters for the traits of interest in the populations. Ebangi and et. al., (2000) estimated direct genetic trends and maternal genetic trends for birth weight in Guadali cattle of 0.022 and $-0.007 \mathrm{~kg}$ per year and for weaning weight of 0.228 and $-0.103 \mathrm{~kg}$ per year, respectively. Thus, the objectives of the paper were investigating the effect of maternal additive genetic and maternal permanent environmental effect on birth and weaning weight of Najdi calves, born in Najdi cattle Research Station located in Khuzestan, Iran, using different models of Mayer and then, estimating genetic and environmental trend for birth weight and weaning weight.

Material and methods In this study, 1249 records of birth weight and weaning weight of Najdi calves were used for estimation of parameters and genetic, phenotypic and environmental trends. The calves were the progeny of 60 sires from 414 cows that calved over a 16-year period. This data collected from 1990 to 2005 . To determine fix effects in model, data analysed with GLM procedure of Minitab program. DFREML software and animal model were used to estimate components of (co) variance and genetic parameters. The models included a direct effect, maternal effect, non-additive maternal permanent environment effect and environmental effect, associated with the animal, fitted as random effects. Sex, calf birth year, season of calving and parity were fitted as fixed effects. Best Linear Unbiased Prediction (BLUP) for direct additive and maternal breeding values were obtained for each animal from the best model, using single trait animal model.

Results Mean and standard deviation of birth weight and weaning weight for Najdi calves calculated $18.08 \pm 3.17$ and $49.56 \pm 13.10 \mathrm{~kg}$, respectively. Based on likelihood ratio test, model 4 was recognized as the best fit model for estimation of birth weight and weaning weight genetic parameters. Genetic and phenotype parameters for birth weight and weaning weight and trend of direct genetic, maternal genetic, environmental and phenotype are presented in table 1 and 2 . In study of American Hereford cattle by Mattos et al (2000) estimates of direct and maternal heritability for birth weight were 0.24 and 0.16 .

Table 1 Estimates of direct and material heritability and components of variance for birth weight and weaning weight

\begin{tabular}{llllllll}
\hline \hline trait & $\mathrm{m}^{2}$ & $\mathrm{~h}^{2}$ & $\sigma_{\mathrm{p}}^{2}$ & $\sigma_{\mathrm{e}}^{2}$ & $\sigma_{\mathrm{m}}^{2}$ & $\sigma_{\mathrm{a}}^{2}$ & $\mathrm{r}_{\mathrm{am}}$ \\
\hline Birth weight & 0.08 & $0.37 \pm 0.11$ & 7.70 & 3.44 & 0.61 & 2.90 & 0.56 \\
Weaning weight & 0.1 & $0.13 \pm 0.06$ & 103.79 & 81.88 & 10.51 & 13.28 & -0.16 \\
\hline \hline
\end{tabular}

Table 2 Trend of direct genetic, maternal genetic, environmental and phenotype

\begin{tabular}{lll}
\hline \hline Estimated trend & Birth weight $(\mathrm{kg})$ & $\begin{array}{l}\text { Weaning weight } \\
(\mathrm{kg})\end{array}$ \\
\hline Direct genetic & $0.06^{*}$ & $0.13^{*}$ \\
Maternal genetic & $0.03^{*}$ & $0.13^{*}$ \\
Environmental & $0.02^{\mathrm{ns}}$ & $0.04^{\mathrm{ns}}$ \\
Phenotypic & $0.07^{\mathrm{ns}}$ & $0.21^{\mathrm{ns}}$ \\
\hline \hline
\end{tabular}

Conclusions The results of this study show that ignoring maternal genetic and environmental effects in analysis model caused to overestimate direct heritability for studied traits. Because of negative genetic correlation between direct and maternal effects for weaning weight trait, methods of selection accounting for both direct and maternal genetic effects would result in greater economic selection response than selection based only on direct genetic effect. Genetic variation in studied years showed ascendant range for two traits, but no emphasizing on one selection index during different years caused to high fluctuation in the breeding value mean of traits in studied population.

\section{References}

De Ebangi, A.L., Erasmus, G.J., Neser, F.W.C. and C.L. Tawah. 2000. South African Journal of Animal Science. 30 (supplement 1). $38^{\text {th }}$ Congress of the South African Society of Animal Science. 36-37.

Mattos, D., Misztal, I. and J.K. Bertrand. 2000. Journal of Animal Science.78 (1), 33-37. 